\title{
Selection of the Optimal Grain-size Distribution of Crushed Stone Sand and Gravel Sand Mix- tures for the Pavement of Truck Haul Roads of Coal Open Pits
}

\author{
Sergey Shabaev ${ }^{1, *}$, Sergey Ivanov ${ }^{1}$ \\ ${ }^{1}$ T.F. Gorbachev Kuzbass State Technical University, 28 street Vesennyaya, Kemerovo, Russian Fed- \\ eration
}

\begin{abstract}
The constant increase in traffic load at mining enterprises forces to look for ways to improve the quality of feeder roads of coal open pits. There is a constant search for tools and methods for improving road pavement to increase the service life of truck haul roads. It is known that haul roads are topped mostly with lightweight flexible pavements due to the peculiarities of moving vehicles. One of the most applicable materials for paving truck haul roads is crushed stone sand mixtures. However, the lack of scientific research aimed at finding ways to improve the riding quality of open pit haul roads and increase the efficiency of open-pit truck haulage operation due to the roads as component of a system did not allow the use of dense-graded mixtures as a pavement for open pit haul roads. In this work, studies were carried out to optimize the grain-size distribution of crushed stone sand mixtures taking into account the physical and mechanical, strength, and deformation properties of the material.
\end{abstract}

\section{Introduction}

A high share in the structure of the cost of rock mass haulage in open pit mining, reaching $15-35 \%$ depending on the capacity of dump trucks [1], accounts for repair and purchase of tires. At the same time, the total cost of tires over the vehicle life reaches $60-80 \%$ of the cost of the truck itself, which raises the question of increasing their life [2]. Almost 55-90\% of tires do not achieve the optimal service life [3]. The main causes of short tire life are mechanical damage (35-60\%) and tread detachment (17-30\%), which testifies mainly to the low quality of open pit haul road pavements [4].

In spring and autumn, when the physical and mechanical properties of base and pavement rocks are the most unfavorable and it is not possible to impose restrictions on the dump truck traffic, the performance of vehicles decreases by $15-20 \%$ due to a significant deterioration in the condition of open pit haul road pavements; traffic often stops [5]. This is due to the fact that existing pavement types topped, as a rule, with overburden rocks or single-fraction gravel are quickly destroyed and difficult to repair, and, therefore, do not provide the required riding qualities. The issue of drainage also remains unresolved. When

*Corresponding author: shabaev81@,rambler.ru 
base and pavement materials are wetted, the subgrade soil is squeezed onto the pavement under the action of loads from the wheels of haul trucks, forming a ground-water suspension, which acts as a lubricant between the pavement and the wheels of the vehicle, significantly reducing adhesion. The presence of a ground-water suspension makes the traffic of open-pit haul trucks impossible, causing its downtime.

In recent years, there has been a significant increase in interest in road pavements and bases made of dense crushed stone mixtures. This is explained, on the one hand, by new technological capabilities during their production and lying, which ensures high quality, and on the other hand, maintainability and ease of pavement maintenance. The feasibility of using dense gravel sand mixtures as a pavement material for open pit haul roads can be substantiated on the basis of their following advantages [6, 7]:

the high dry bulk density significantly (depending on the gravel content its strength is 3-12 times that of single-sized gravel) reduces the process of grinding stone material under the mechanical impact of automobiles, which reduces the speed of the process of formation of corrugations and potting and, as a result, increases evenness of pavement;

ease of pavement repair and maintenance allows constant maintaining its high riding qualities, which generally increases the speed of dump trucks and, consequently, their performance, the service life of the pavement, and also reduces the cost of haulage and the downtime of dump trucks;

- $\quad$ use of dense crushed stone sand mixtures allows reducing rolling resistance by 15 $25 \%$, which generally leads to a decrease in fuel consumption and, accordingly, cost of transportation.

\section{Materials and methods}

The lack of scientific research aimed at finding ways to improve riding qualities of open pit haul roads and increase the performance of dump trucks due to the roads as a component of the system did not allow using dense mixtures as a material for open pit haul road pavement.

On the one hand, the optimal grain-size distribution of pavement mixtures should have a maximum dry bulk density, which helps to reduce the degree of water filtration through the pavement and overwetting of the base, and on the other hand, high deformation and strength characteristics to absorb the load from heavy-duty dump trucks. To select a truly optimal particle-size distribution, we consider the effect of the content of individual particles in the mixture on the properties of the layer made from it.

As a result of laboratory tests, it was found that:

- the dependence of the dry bulk density on the content of particles of a certain size in the mixture has the form of an asymmetric parabola; with a gradual increase in the total residue on a sieve with an aperture diameter $d$, the density of the dry bulk first slowly increases to a maximum, and then drops sharply even with a slight increase in the total residue.

- the dependence of the elastic modulus of the layer on the content of particles of a certain size in the mixture has the form of a hyperbola; with a gradual increase in the total residue on a sieve with an aperture diameter $d$, the elastic modulus of the layer grows rapidly, then stabilizes, and when a certain limit is reached, the process of intensive growth resumes.

- the higher is the value of the total residue on the sieve with an aperture diameter $d$, the higher is the strength of the layer. 


\section{Results}

Based on the obtained dependences, it is possible to optimize the grain-size distribution of crushed stone sand mixtures taking into account physical, strength and deformation characteristics:

1. In order for the layer made from the crushed stone sand mixture to have a high dry bulk density, the content of grains of a certain size should not exceed a certain value $A$. Thus, we obtain the first inequality of the system: $P . O_{d} \leq A$, where $P . O_{d}$ is the total residue on the sieve with mesh sizes $d$.

2. An intensive drop in the elastic modulus is observed when the total residue on the sieve with an aperture diameter $d$ is less than a certain value of $B$, on the basis of which, we can obtain the second inequality of the system: $P . O_{d} \geq B$.

3. The more large particles are contained in the crushed stone sand mixture, the higher is the strength performance of the layer made from this mixture. Based on this, we can obtain the third inequality of the system: $P . O_{d} \rightarrow \max$.

4. Based on the process requirements for the mixtures of the optimal grain-size distribution, it is necessary that the interval of change in the total residue on each sieve has a value of at least $15-25 \%$. Given this condition, we can obtain the fourth inequality of the system: $P . O_{d \max }-P . O_{d} \min \geq 15 \ldots 25$, where $P . O_{d \max }, P . O_{d \text { min }}$ are, respectively, the maximum and minimum permissible total residues on the sieve with an aperture diameter $d$.

As a result of combining the obtained inequalities, we obtain the system:

$$
\left\{\begin{array}{l}
P . O_{d} \leq A \\
P . O_{d} \geq B \\
P . O_{d} \rightarrow \max \\
P . O_{d} \max -\Pi . O_{d \min } \geq 15 \ldots .25 .
\end{array}\right.
$$

The system does not have a unique solution (Fig. 1), however, the interval $P . O_{d} \in[A-15 \ldots 25 ; A]$ is the most optimal solution, since in this case the layer made from a mixture with a given content of particles of a given size has a dry bulk density close to the maximum, a fairly stable interval of elastic modulus and maximum strength performance.

Thus, the optimal grain-size distribution of the crushed stone sand mixture is the one that falls into the interval bounded "from above" by the maximum possible total residue on the $i$-th sieve under the condition of ensuring the highest dry bulk density, and "from below" - by the maximum possible total residue according to the conditions of their mixing technology, i.e. the difference between the "upper" boundary of the optimal area and the "lower" one should not be below the limits of $15-25 \%$. Based on the conclusion we design the grain compositions of mixtures with different maximum sizes of grains of the mixture (Table). 


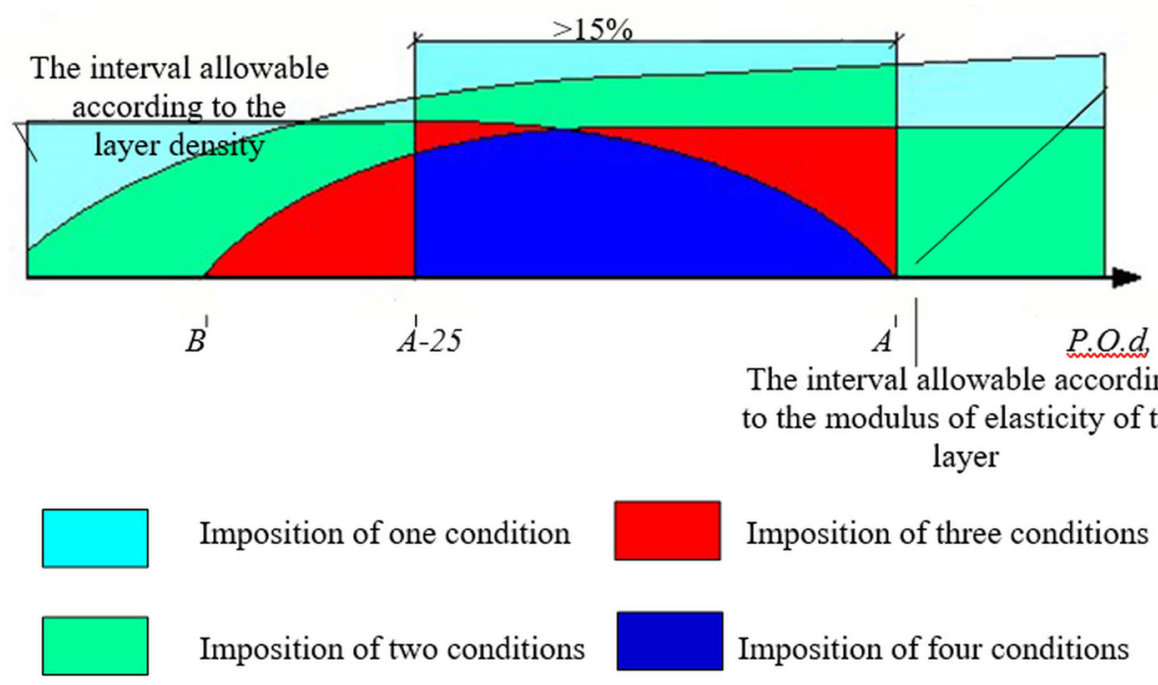

Fig. 1. Graphical presentation of a solution to the system of inequalities.

Table 1. The results of the optimization of grain-size distribution of crushed stone sand mixtures of various grain sizes for paving open pit haul roads.

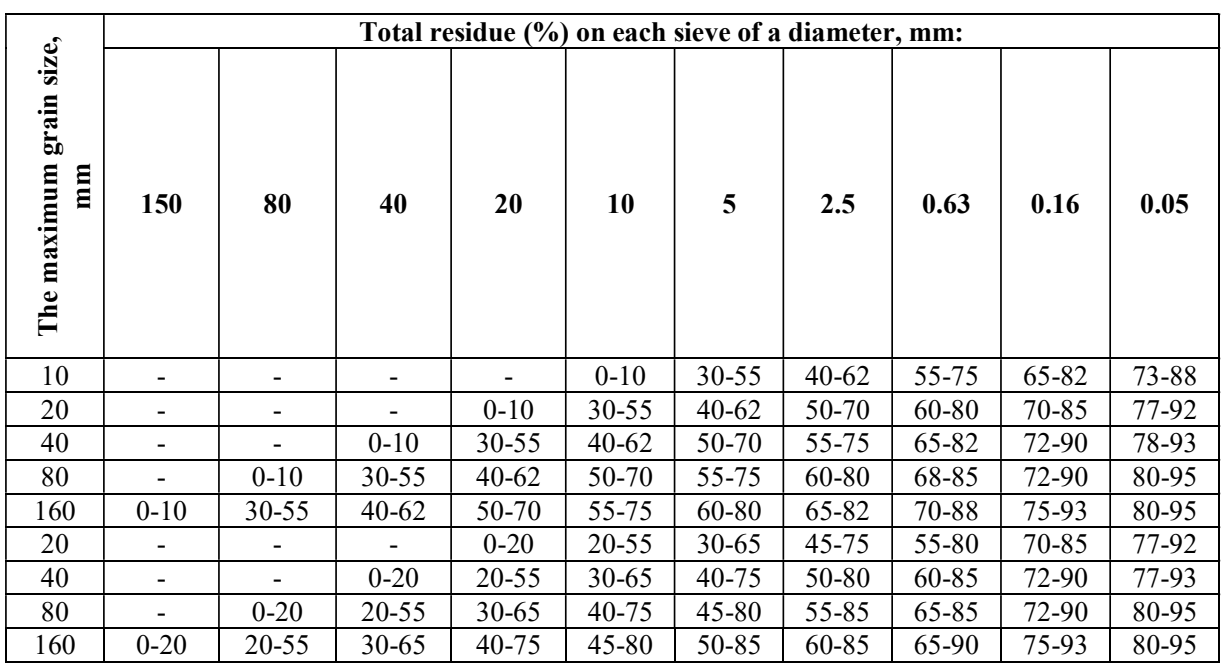

\section{Conclusions}

The optimal grain-size distribution of crushed stone sand mixture is one that falls within the range bounded from above by the maximum possible total residue on each sieve under the condition of ensuring a high dry bulk density, and from below - by the maximum possible total residue on each sieve according to the conditions of their mixing technology. 


\section{References}

1. A. V. Rybak, Assessment tire costs, 11, 7 (2003)

2. V. F. Petrov, V. M. Medvedev, V. V. Koshevoy, Heavy dump trucks, 10, 8 (2000)

3. D. Ingle, Mining Journal, 4, 89 (1994)

4. I. V. Zyryanov, Mining Journal, 3, 23 (1997)

5. O. P. Afinogenov, V. V. Ivanov, Theoretical foundations for ensuring the durability of rigid pavements of mining truck haul road (Kuzbass University Publisher, Kemerovo, 2001)

6. V. M. Yumashev, K. Turenk, Motor ways, 7, 42 (1990)

7. B. F. Babkov, Motor ways (Transport, Moscow, 1983) 